\title{
Problems with Deducing Ionospheric Plasma Convection Patterns
}

\author{
J. J. SOJKa AND R. W. SCHUNK
}

Center for Atmospheric and Space Sciences, Utah State University, Logan

\begin{abstract}
It is well-known that convection electric fields have an important effect on the ionosphere-thermosphere system at high latitudes and that a quantitative understanding of their effect requires a knowledge of the plasma convection pattern. Consequently, convection electric fields have been measured by a variety of techniques, including satellite, rocket, and balloon-borne probes, optical tracking of ionized barium clouds, incoherent scatter observations of drifting $F$ region plasma, and coherent scatter observations of drifting $E$ region irregularities. Since all of these measurement techniques provide information on only a limited spatial region at any time, the construction of the overall convection pattern requires a synthesis of data obtained at a variety of places and times. Some of the problems associated with this procedure are examined in this study using incoherent scatter radar data as an example. In this case the main problem stems from the great variability of the convection electric field. Even for very similar magnetic and IMF conditions, the synthesis of convection data obtained on different days produces a convection pattern which has a fairly large uncertainty. For the case considered, the uncertainty is sufficiently large so that the characteristic differences between the H. Volland [1978] and R. A. Heelis et al. [1982] convection models cannot be clearly identified. In comparison to this uncertainty, the uncertainties associated with assuming how corotation is driven and with transforming velocities between geographic and geomagnetic coordinate systems are negligible. The selection of the "correct" magnetic coordinate system is also less important in view of the convection variability.
\end{abstract}

\section{INTRODUCTION}

During the last decade, a major effort has been devoted to studying the effect that magnetospheric electric fields have on the high-latitude ionosphere and neutral atmosphere. Very early, it became apparent that a quantitative understanding of the effect of magnetospheric electric fields could not be obtained without a knowledge of the plasma convection pattern. Experimentally, the convection pattern and associated electric fields have been studied by a variety of techniques, including satelliteand rocket-borne probes [Heppner, 1972, 1977; Maynard, 1974; Kelley et al., 1975; Heelis et al., 1976], balloon-borne probes [Mozer and Lucht, 1974], observations of the drift of clouds of ionized barium [Haerendel et al., 1967], incoherent scatter observations of the drift of the $F$ region plasma [Doupnik et al., 1972; Evans et al., 1980; Foster et al., 1981], and coherent scatter observations of the drift of $E$ region irregularities [Greenwald et al., 1978].

All of the measurement techniques described above provide information on only a limited spatial region at any instant of time, requiring that the overall pattern of high-latitude electric fields be synthesized by combining observations made at a variety of places and times. Since individual measurements have shown the convection pattern to be both structured and highly variable, the synthesis of measurements made at different places and times leads to "average" rather than "instantaneous" convection patterns. Nevertheless, these average convection patterns clearly show that most of the time plasma convection exhibits a two-cell structure with antisunward flow over the polar cap and return flow at lower latitudes.

In an effort to describe plasma convection on a global scale, several empirical models have been developed. Foremost among these are the Volland-Heppner [Heppner, 1977; Volland, 1978] and Heelis et al. [1982] convection models. Both models require similar inputs, such as the total cross-tail electric potential, the

\footnotetext{
Copyright 1986 by the American Geophysical Union.
}

Paper number 5A0670.

0148-0227/86/005A-0670\$05.00 diameter of the polar cap, the potential falloff rate outside the polar cap, the antisunward displacement of the pattern from the magnetic pole, the rotation of the pattern relative to the noonto-midnight magnetic meridian, and the degree of asymmetry between the two convection cells. However, there are important differences between the two models. For the Heelis model the maximum potential in the convection cells is distributed along a line, while for the Volland-Heppner model it occurs at a point. Furthermore, for the Heelis model the electric field in the polar cap is not uniform, in contrast to that for the simplest VollandHeppner model. The Heelis model can also describe features such as the dayside throat and Harang discontinuity.

The different features that are incorporated in the Heelis and Volland-Heppner models were based on a synthesis of measurements, and no doubt reflect magnetospheric processes. However, the extent to which these average convection models can describe the instantaneous convection pattern is not clear. Also, it is not clear to what extent magnetospheric signatures have been distorted during the "averaging" process.

The availability of incoherent scatter radar data obtained simultaneously from multiple sites provides a unique opportunity to observe the instantaneous plasma convection pattern and hence to determine the extent to which the existing average convection models can describe this pattern. Although the comparison of model with data appears to be straightforward, there are problems owing to uncertainties connected with the data interpretation. For example, the radars cover a limited latitudinal range, and hence the identification of an instantaneous convection pattern will be subject to uncertainties. Also, in order to obtain information about magnetospheric convection features it is necessary to transform the observed plasma velocities from the corotating geographic frame to a magnetic frame. However, there are uncertainties associated with the transformed velocities. Furthermore, radar plasma convection patterns are frequently averaged in an effort to remove the rapid temporal fluctuations associated with substorms. The extent to which the averaging process distorts the instantaneous convection pattern is also not clear.

In section 2 we critically look at the various reference frames 
and coordinate systems used to represent the magnetospheric electric and magnetic fields in the ionosphere. Based on this discussion, in section 3 we then show the relative effects of transformations between these frames and the sensitivity of present day observations of ionospheric convection velocities. Fits of the semiempirical Volland and Heelis models to the Foster model of ionospheric convection are shown and discussed in section 4 . The major problem facing modelers, that of modeling the time dependence of the magnetospheric electric field, is addressed in section 5 .

\section{IONOSPHERIC CONVECTION REFERENCE FRAMES}

The high-latitude ionospheric plasma moves perpendicular to ionospheric magnetic field lines by $\mathbf{E}$ x B drifting. Two major sources of this drift exist. The first is corotation in which the plasma "tends" to corotate with ground-based observers in a geographic frame. This can be readily seen from incoherent scatter radar data at mid-latitudes, where the observed ionospheric plasma velocity is "approximately" zero relative to corotating ground observers [see Foster et al., 1981]; how close to zero will be discussed in section 3. The second main source results from magnetospheric electric fields which map down into the ionosphere along geomagnetic field lines. Drifts associated with these electric fields are again readily observed by ground-based and satellite instruments [see Heelis et al., 1983]. This second electric field source is not well understood. The magnetospheric electric field in the ionosphere arises from the fact that magnetic field lines are approximately equipotentials, and hence any potential distribution maintained in the magnetosphere is mapped along geomagnetic field lines into the ionosphere. Therefore the magnetospheric electric field in the ionosphere is closely coupled to the magnetic field geometry linking the ionosphere and magnetosphere.

For ionospheric modeling, only an ionospheric representation of the magnetospheric electric field is needed. Unfortunately, no rigorous method of producing this exists at the present time. Radars, especially the incoherent scatter radars, are able to observe the ionospheric convection over a wide range of latitudes (10's of degrees) and at all local times, while satellites cover almost all latitudes at a few local times. These data sets, when combined, lead to the best empirical information on the ionospheric electric field [Heelis et al., 1983]. However, with regard to ionospheric and thermospheric modeling, whether global or local, a knowledge of the global ionospheric electric field is required. In the subsequent sections, we discuss how semiempirical models of ionospheric electric fields are used to complement the limited observations. For model calculations, full vector transformations are carried out in going from the selected magnetic frame to the geographic frame. The electric field distribution is defined in terms of latitude and local time in the magnetic frame. This choice of frame for the ionospheric electric field arises from our simple arguments concerning the electric field mapping from the magnetosphere to the ionosphere, which strongly favors a magnetic frame over a geographic frame. However, no unique magnetic frame exists.

Empirical convection data are usually presented in terms of invariant latitude-magnetic local time (MLT), geographic latitude-local Time (LT), or a combination of these two coordinate frames [Heelis et al., 1976, 1983; Evans et al., 1980; Foster et al., 1981; de la Beaujardiere et al., 1983; van Eyken et al., 1984]. The magnetic coordinates are obtained by magnetic field line tracing using standard empirical magnetic field models, such as the
IGRF 80 model [IAGA, 1981]. This procedure results in a unique invariant latitude and magnetic local time for each geographic ground location [Muldrew and Vickrey, 1982; van Eyken et al., 1984]. The MLT for each site is equal to its LT, plus a constant offset which varies from site to site. In contrast, theoreticians and modellers use a simplified representation of the magnetic field, such as a magnetic dipole, and consequently a magnetic frame fixed to the dipole axis is obtained [Sojka et al., 1979]. Magnetic dipole latitude and MLT are therefore the coordinates in this dipole frame.

Figure 1 contrasts magnetic latitude, as defined by the IGRF 80 and dipole models, for various geographic latitudes. The dipole axis used for the dipole reference frame is at a geographic latitude and longitude of $78.6^{\circ} \mathrm{N}$ and $288^{\circ} \mathrm{E}$, respectively. Three sets of data are shown, each corresponds to points lying in the magnetic meridian plane through a ground-based radar site. The dipole latitudes agree fairly well with the computed invariant latitudes. At Chatanika, the dipole latitude is about $2^{\circ}$ less than the corresponding invariant latitude. Hence over magnetic latitudes from $60^{\circ}$ to $80^{\circ}$ the dipole model latitude is within $2^{\circ}$ of the IGRF 80 model.

However, the choice of a magnetic frame is further complicated because a consideration of how the electric field is generated in the magnetosphere is relevant. In both the dipole and IGRF 80 models, the latitude is independent of UT; nevertheless, the magnetic field line experiences a UT variation in its equatorial crossing point location. This variation is associated with the magnetosphere's topology and is included in more sophisticated magnetic field models, such as the Olsen and Pfitzer tilt model (W. P. Olsen and K. A. Pfitzer, unpublished manuscript, 1977). Using this model, Sojka et al. [1983a] studied the diurnal stretching and bending that a field line experiences as the magnetic pole rotates about the geographic pole. In Figure 1 the vertical bar at $68^{\circ}$ geographic latitude represents the diurnal stretching a single field line experiences. The stretched latitude is determined from the equatorial radial distance, which is then converted to an effective dipole latitude. This field line, which has an invariant latitude of $\sim 68^{\circ}$ on the dayside, stretches to about $74^{\circ}$ on the nightside near midnight. At present, no details are available on how this diurnal dependence affects the mapping of the magnetospheric electric field into the ionosphere, although the work of Mroz et al. [1979] suggests there may be a magnetospheric dependence. Hence the choice of a particular magnetic coordinate system in the ionosphere is at present somewhat arbitrary, since none of the currently used coordinates reflect high-latitude magnetospheric topology.

This can be further seen in Figure 2, where the diurnal difference between magnetic local time and the local time of the flux tube used in Figure 1 is plotted for the three magnetic field models. The IGRF 80 model gives a constant difference between these two local times, whereas the W. P. Olsen and K. A. Pfitzer (unpublished manuscript, 1977) model, with its more complex local time dependence, gives a diurnal difference between -1.4 and -2.4 hours. In the case of the authors' dipole the MLT-LT diurnal variation is not due to magnetospheric topology, but is a property of how MLT for the tilted reference frame is defined (see earlier discussion). The MLT-LT modulation in Figure 2 for the dipole model is about $1 / 2$ an hour. This modulation implies that the corotation velocity of a ground-based observer in the magnetic frame is not constant, but is UT (diurnal) dependent. Between 0 and 8 UT in Figure 2, 8 hours of LT and 


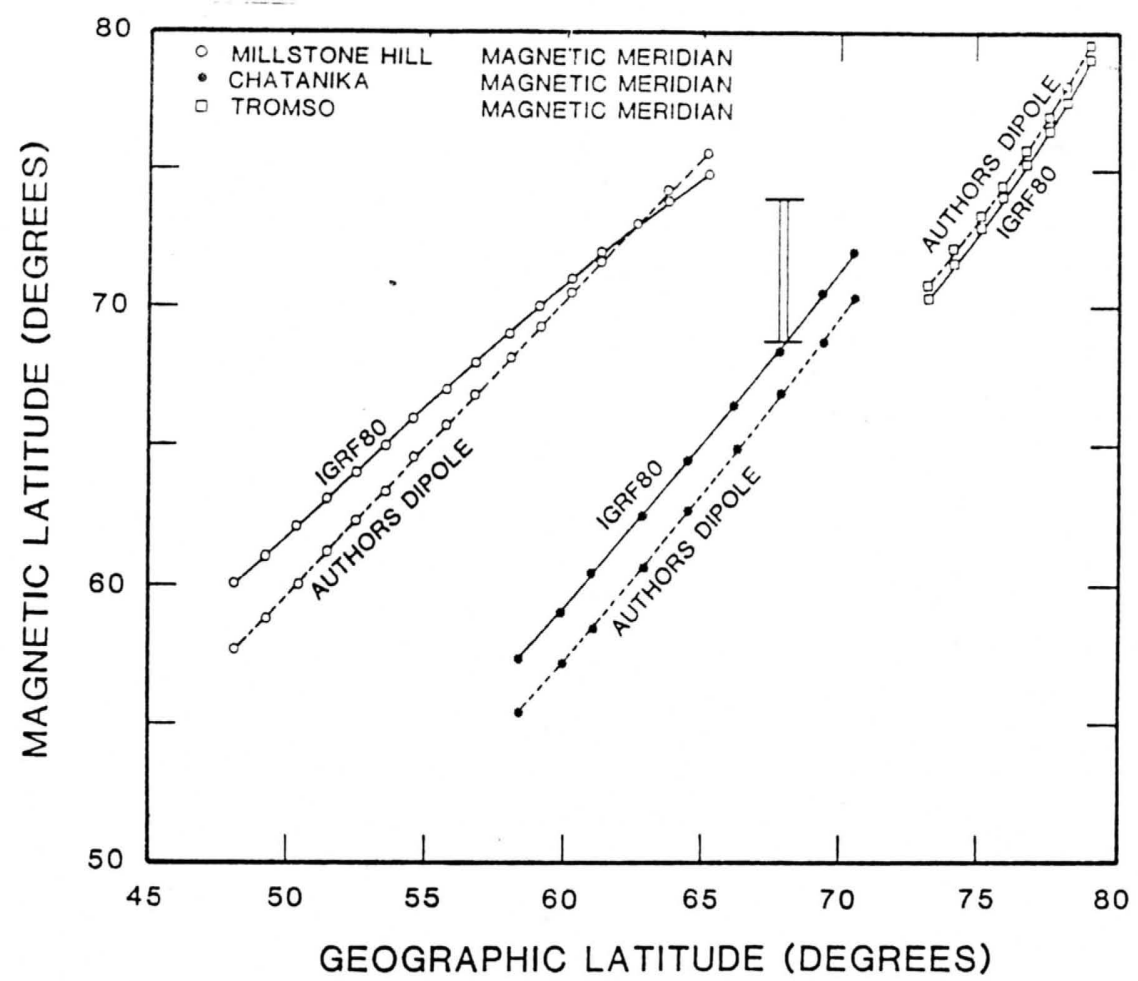

Fig. 1. Comparison of magnetic latitudes deduced from three different magnetic field models: IGRF 80 (solid line), authors' magnetic dipole (dashed line), and W. P. Olsen and K. A. Pfitzer (unpublished manuscript, 1977) (vertical bar). The comparison is for the Millstone Hill, Chatanika, and Tromso magnetic meridians.

IGRF 80 MLT elapse, but 8.5 hours of dipole MLT elapse. This UT (diurnal) difference has a seasonal dependence, i.e., it depends on the latitude of the sun. It is minimal near equinox, but near solstice it can cause a modulation of the corotation velocity of $\simeq 10 \%$. The magnetic local time coordinates currently used do not reflect unique magnetospheric electric field properties and hence have problems similar to that discussed above for magnetic latitude.

\section{Velocity TRANSFORMATIONS}

To model ionospheric convection, a magnetospheric electric field distribution and a corotation electric field are defined in

Fig. 2. UT variation of the magnetic local time relative to the geoauthors'mal time at a single location for three magnetic field models: (unpublished dipole (thick solid line), W. P. Olsen and K. A. Pfitzer line). terms of the dipole coordinates. In the magnetic frame, it is generally assumed that magnetospheric convection does not exhibit a local ionospheric diurnal modulation (longitude dependence). For a realistic magnetic field topology this assumption may prove to be incorrect [Mroz et al., 1979]. With regard to corotation, the physical mechanisms which cause the ionosphere to corotate are not well understood. Observationally, mid-latitude ground-based incoherent scatter radars indicate that the $F$ region generally has only a "small" relative velocity with respect to a corotating observer. Also, the existence of mid-latitude evening sector troughs are simplistically associated with regions of plasma stagnation; i.e., where there is a corotational velocity which is opposite and approximately equal to the magnetospherically induced convection velocity. However, in the mid- and high-latitude regions the physics of how an electric field is generated to produce a corotating $F$ region is not understood. Hence it is not clear to what extent the plasma actually corotates. In fact, in our previous studies we have described this uncertainty simply by saying that "the $F$ region has a tendency to corotate." In the following paragraph, we discuss the significance of this problem to large-scale convection.

If the plasma is assumed to perfectly corotate in the geographic frame, then in the magnetic frame the corotation velocity will be UT (longitude) dependent. An alternative assumption is that corotation is perfect in the magnetic frame. This is plausible, since one can imagine a corotational electric field tied to the geomagnetic field. In this case, the corotation velocity would be UT (longitude) dependent in the geographic frame. Hence when observed by a ground-based observer, the plasma would not be stationary. The question arises as to how significant these UT (longitude)-dependent departures from corotation are. Under most conditions the departures from corotation, 
which are associated with the properties of the transformations, are less than $10 \mathrm{~m} / \mathrm{s}$. This magnitude is small compared with the current sensitivity of incoherent scatter radar measurements [Foster et al., 1981].

The differences between a velocity in the magnetic and geographic frames due to the above described "corotation" assumptions and transformations are at present significantly smaller than experimental uncertainties and can be ignored. Following on from the discussion in section 2, another difference might arise in how the whole velocity pattern is viewed by different observers. The differences between the dipole frame and the IGRF frame depend on the location (see Figure 1). In fact, by changing the location of the dipole axis better agreement can be obtained between the two magnetic latitudes. For example, if the dipole axis is moved toward Chatanika by about $2^{\circ}$, the dipole latitude scan line shown in Figure 1 for Chatanika would agree better with the IGRF 80 values. However, this change in dipole axis location would cause the Tromso agreement to degrade by about $2^{\circ}$. Thus the choice of a dipole axis location is uncertain to at least $\pm 2^{\circ}$ about a point which is also uncertain by a similar amount. How this uncertainty manifests itself in transformations is now discussed.

Figure 3 shows diurnal convection velocities on three magnetic meridians for the Foster [1983] electric field model. For simplicity, the corotation electric field is omitted. The velocities are shown in dipole magnetic coordinates for each meridian and it is apparent that the three patterns are identical. Based on the work of Mroz et al. [1979] if a UT (diurnal) dependence existed in the magnetospheric $E$ field due to the diurnally changing magnetic field, the three sites would see different magnetospheric patterns. However, the magnitude and UT form of these fields is currently unknown. When viewed in the geographic frame, these velocities shown in Figure 3 are simply rotated and shifted in local time. The shift in local time arises from the difference in MLT and LT as a function of latitude along a magnetic meridian. The rotation arises because a northward orientation in the magnetic frame is, in general, not a northward orientation in the geographic frame. This shift in LT and rotation are entirely distinct from the smaller velocity corrections associated with the transformation discussed earlier. Thus the three identical sets of velocities shown in Figure 3 when presented in a geographic latitude-LT frame would no longer be identical. Such differences in convection patterns have been presented before [Sojka et al., 1980a]. Indeed, a presentation in any reference frame (coordinate system) other than the frame from which the pattern was generated will result in the pattern being longitude dependent. Our discussions have shown that no unique magnetic reference frame currently exists and have demonstrated that from a modeling viewpoint the uncertainty in locating a magnetic dipole axis is at least $\pm 2^{\circ}$ if convection observations from several longitudes are contrasted. The same kind of uncertainty applies to the reference frames defined by empirical magnetic field models (see Section 2).

Figure 4 shows how the three convection patterns in Figure 3 appear if they are presented in a reference frame whose pole is located $3^{\circ}$ away from the magnetic pole used for Figure 3. This small offset is chosen to show the possible differences which could be associated with choosing a nonunique magnetic frame. The differences between Figures 3 and 4 all arise from the local time and rotation shifts to the individual velocities; the velocity transformation correction is negligible. In Figure 4, the corresponding noon and midnight reversal regions differ by about 1 hour between "Chatanika"(top panel) and "EISCAT" (bottom panel). The orientation of the westward flow in the 1400 to 2000 MLT sector is purely westward at EISCAT, while at Chatanika it has a $(\simeq 40 \%)$ northward component. At Millstone Hill, the whole pattern is moved to lower latitudes because the $3^{\circ}$ shift in pole location is from the original magnetic pole location $\left(78.4^{\circ}\right.$ $\left.\mathrm{N}, 288^{\circ} \mathrm{E}\right)$ toward the geographic pole. The location of the magnetic pole used for Figure 4 is $81.4^{\circ} \mathrm{N}, 288^{\circ} \mathrm{E}$. For this shift, convection features are seen earlier at Chatanika than at "Millstone Hill," and about an hour later in MLT at EISCAT (see Figure 4).

The uncertainty in choosing which magnetic frame best represents the magnetosphere is significant and the differences associated with this uncertainty are measureable. In Figure 4, local time differences of up to an hour and vector orientation differences of up to $25^{\circ}$ are present between different longitudes. Such differences are within the resolution of the incoherent scatter radars. Unfortunately, since the radars are separated in local time, and hence UT, substorm activity severely complicates the above test. The consequences of substorms will be addressed in section 5 .

\section{IONOSPHERIC ELECTRIC FIELD MODELS}

In model studies of both the ionosphere and thermosphere extensive use has been made of very simple convection models [Quegan et al., 1982; Rees et al., 1984; Roble et al., 1984; Sojka et al., 1979]. Also, when model calculations are compared with observed ionospheric data, the model representation of the convection pattern is again typically very simple (see, for example, Sojka et al. [1980a, $b]$ ). These simple models are usually of the Volland or Heelis type [Volland, 1978; Heelis et al., 1982]. Such models are particlarly attractive, because one model can represent a wide variety of magnetospheric conditions simply by changing a few parameters.

Empirical convection models, on the other hand, are more difficult to generalize. However, a wide range of empirical models are currently available [Heppner, 1977; Oliver et al., 1983; Foster, 1983]. Each of these empirical models applies for a particular geomagnetic and IMF condition and is based upon a subset of observations. For example, the Foster [1983] model, used in section 2, is a model based on averaging 9 days of data characterized by an average $K p \simeq 3$ and the IMF mainly in the toward sector. Because neither the ground-based radar nor satellite coverage is complete in latitude and LT, the empirical models lack global coverage. By using multiple sites and satellites, this problem is being tackled [Heelis et al., 1983; de la Beaujardiere et al., 1983]. However, at present the simpler models are still necessary in order to obtain a global representation of ionospheric convection.

Figure 5 shows how the Foster [1983] electric field pattern can be simulated by the Volland and Heelis models. The three panels show contours of electric potential at $5 \mathrm{kV}$ intervals in a dipole latitude and MLT frame. The top panel is the Foster convection electric field, while the lower two panels are the Volland (middle panel) and the Heelis (bottom panel) models. In each case no contours are shown poleward of $75^{\circ}$, the upper latitudinal limit of the Chatanika radar used to collect the data for the Foster model. However, it should be noted that the polar region is associated with the largest differences between the Volland and Heelis models. The parameters for the Volland and Heelis patterns were chosen to give a cross polar cap potential of $70 \mathrm{kV}$; 


\begin{tabular}{|l|l|l|l|l|}
\hline $100 \mathrm{M} / \mathrm{S} \cdot$ & $200 \mathrm{M} / \mathrm{s}-$ & $500 \mathrm{M} / \mathrm{S} \rightarrow$ & $1000 \mathrm{M} / \mathrm{s} \rightarrow$ & $2000 \mathrm{~m} / \mathrm{s} \longrightarrow$ \\
\hline
\end{tabular}

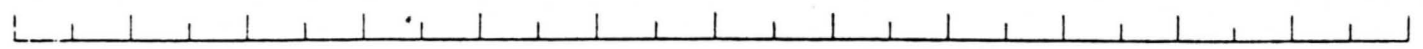
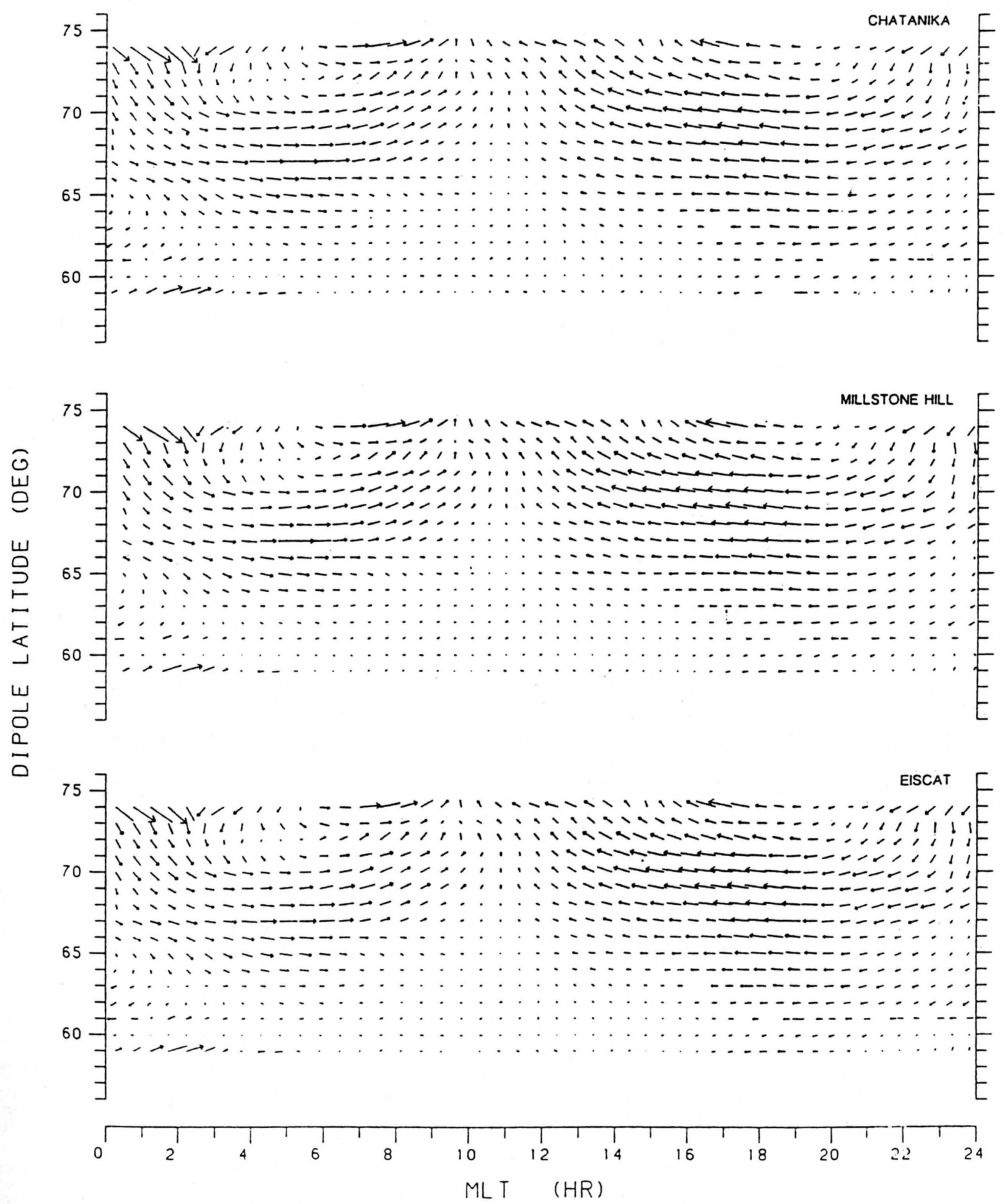

Fig. 3. Foster [1983] convection model velocities presented in the authors' dipole latitude-MLT reference frame at three locations: EISCAT (bottom), Millstone Hill (middle), and Chatanika (top). 


\begin{tabular}{|l|l|l|l|l|}
\hline $100 \mathrm{M} / \mathrm{s} \cdot$ & $200 \mathrm{M} / \mathrm{s}-$ & $500 \mathrm{M} / \mathrm{S} \rightarrow$ & $1000 \mathrm{M} / \mathrm{s} \rightarrow$ & $2000 \mathrm{M} / \mathrm{s} \rightarrow$ \\
\hline
\end{tabular}
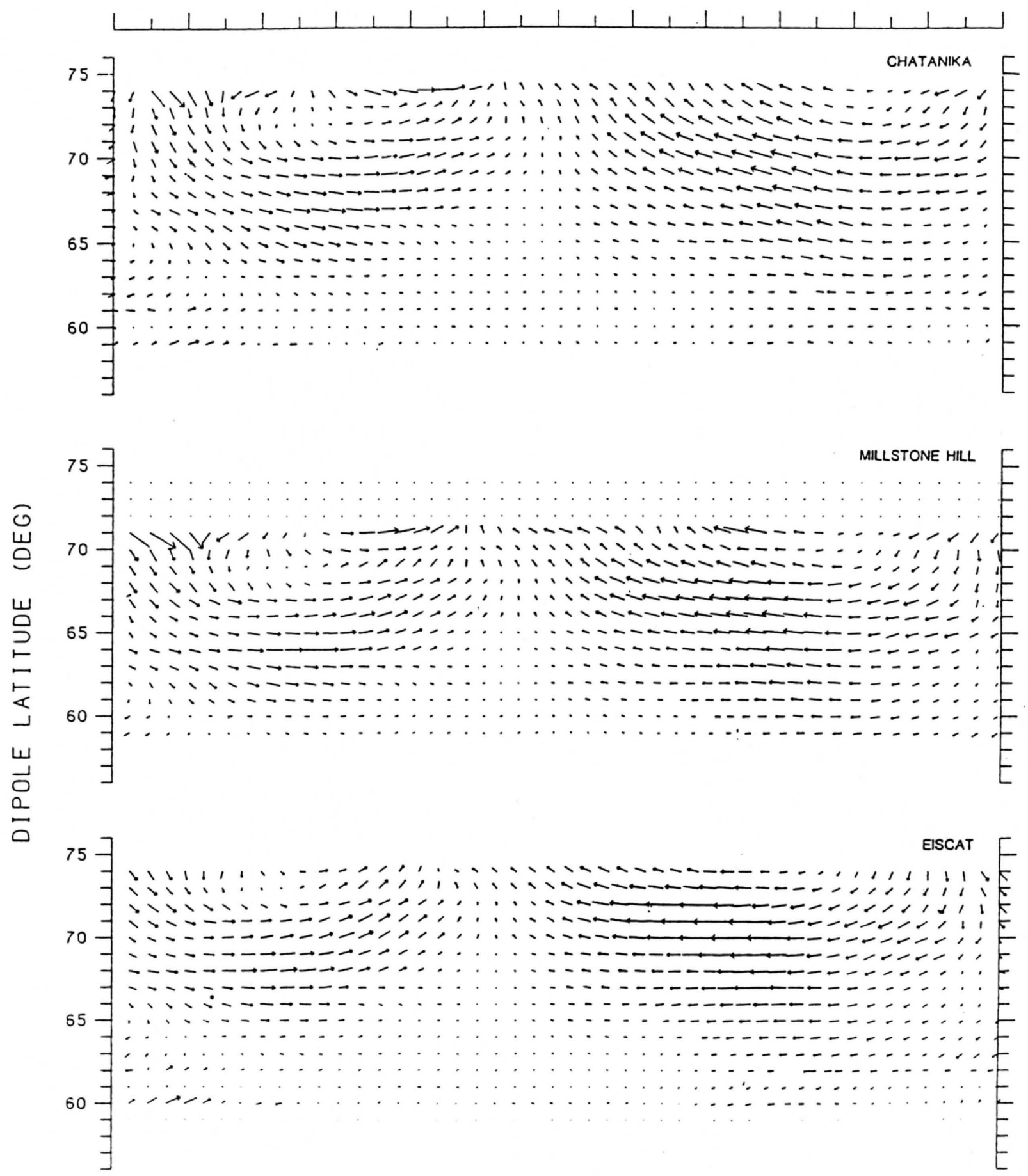

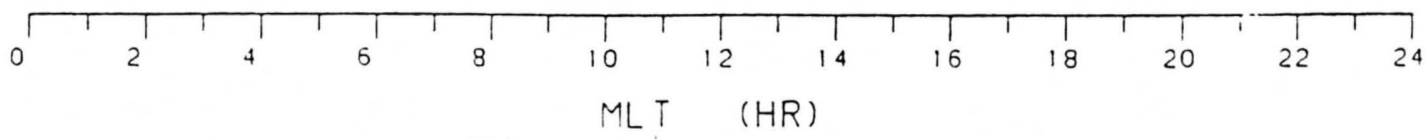

Fig. 4. Foster [1983] convection model velocities presented in a new reference frame whose pole is located $3^{\circ}$ closer to the geographic pole than the dipole frame which contains the Foster electric field distribution. The velocity patterns are presented for the same three locations as in Figure 3. 

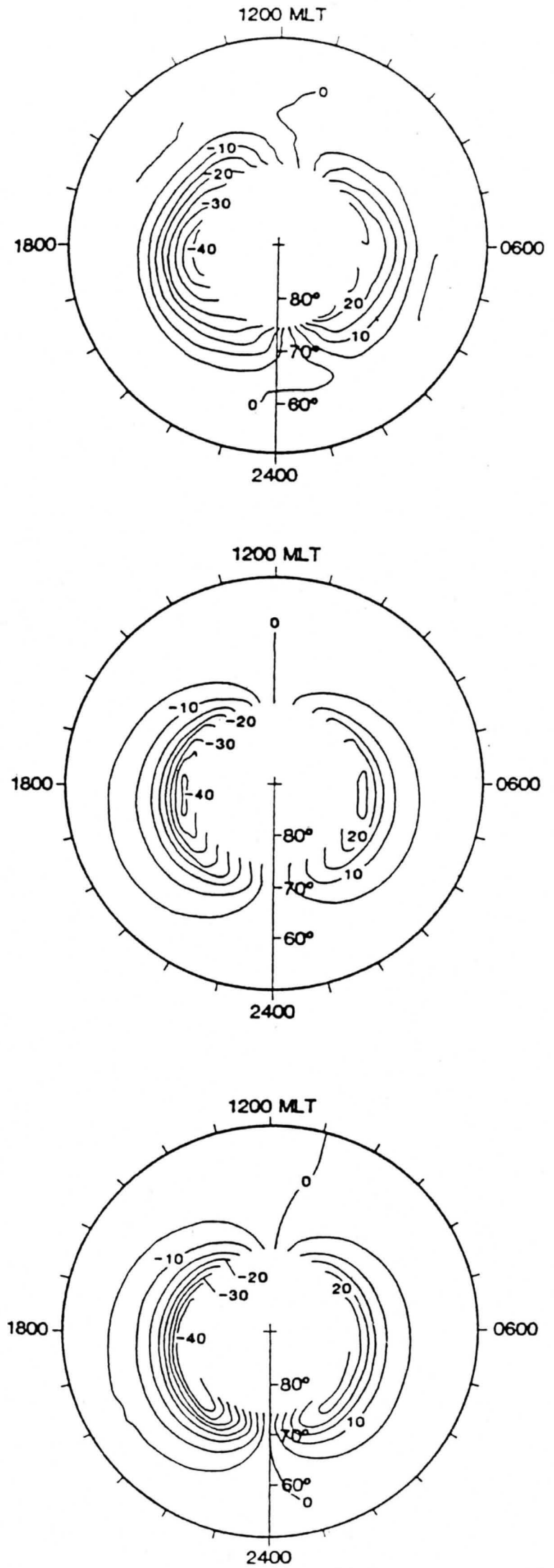

Fig. 5. Contours of electric potential for three magnetospheric electric field models in the authors' dipole latitude-MLT reference frame. The Foster [1983] electric field distribution is shown in the top panel, while comparable Volland [1978] and Heelis [1983] patterns are shown in the middle and bottom panels, respectively. with $\sim 44 \mathrm{kV}$ on the dusk side and $26 \mathrm{kV}$ on the dawn side; a polar cap radius of $17^{\circ}$ with an antisunward shift of $\sim 21 / 2^{\circ}$; and an inverse fourth power of sine colatitude fall-off equatorward of the polar cap. These features are similar to those deduced by Foster. It should be noted that the simulated patterns were not obtained by making least square fits to the Foster data set. They represent only a zeroth-order comparison in which the patterns are similar. The following discussion will highlight why a sophisticated "least squares fit" would be physically not very useful.

On the dayside, both the Volland [1978] (middle) and Heelis [1982] (bottom) models look very similar to the Foster [1983] model (top). In the dawn sector, the center of the cell is quite small for the Volland model and extended for the Heelis model; the Foster model shows the inner contour to be broken and spread over a wide range of local times. Outside this inner contour, the Volland model looks more similar to the Foster model than does the Heelis model. Around dusk the Volland potentials are in better agreement with the Foster potentials, while in the midnight sector there are three distinct patterns. In the midnight sector, the high latitude parts of both the Volland and Heelis patterns show a region of polar cap potential. The Foster model shows what might appear to be such "antisunward" flow potentials at midnight.

To look in more detail at this disagreement between the two convection models and the Foster data model, the westward convection velocity at 1800 MLT is plotted in Figure 6 as a function of dipole latitude for the three models. Up to a latitude of about $69^{\circ}$, the Volland [1978] and Heelis [1982] models look similar to the Foster model. Poleward of this latitude, and especially poleward of $72^{\circ}$ (in the polar cap), the flows are in an opposite direction to the Foster model. This difference in direction is highly significant, since it represents the antisunward closure flow of the dusk convection cell. Its absence in the Foster data causes problems for the Heelis and Volland models. The 1800 MLT meridian was deliberately chosen for the comparison since the westward flows are about the largest flows seen in the Chatanika observations and are fairly uniform over a large latitude and MLT sector, which act to produce reliable radar measurements. The error bars shown in Figure 6 on the Foster curve represent the radar measurement sensitivity [Foster et al., 1981]. Clearly, the radar's sensitivity is adequate to resolve the model (Volland or Heelis) flow reversal if it had occurred at these latitudes.

The error bars in Figure 6 represent the radar measurement accuracy, whereas the Foster model corresponds to an average over 9 days of Chatanika radar data [Foster, 1983]. These data were for similar magnetic activity levels and season, and except for 2 days were in the toward IMF sector. Figure 7 shows the observed westward flow at 1800 MLT as a function of invariant latitude for these 9 days along with the Foster model profile at 1800 MLT. The full 9 days of radar data are presented by Foster et al. [1981]; the curves shown in Figure 7 were extracted from this source. These data clearly show the difficulty a modeler has in determining an adequate representation of the ionospheric electric field pattern. The variation of these nine data sets greatly exceeds the radar sensitivity. Hence although the data are apparently for similar conditions, their dependence on small differences in these conditions is strong. The latitudinal variations on June 23, 1978, June 29, 1978, and July 14, 1979, look completely different from the Foster model at latitudes equatorward of $\sim 69^{\circ}$, and yet all curves are for similar magnetic 


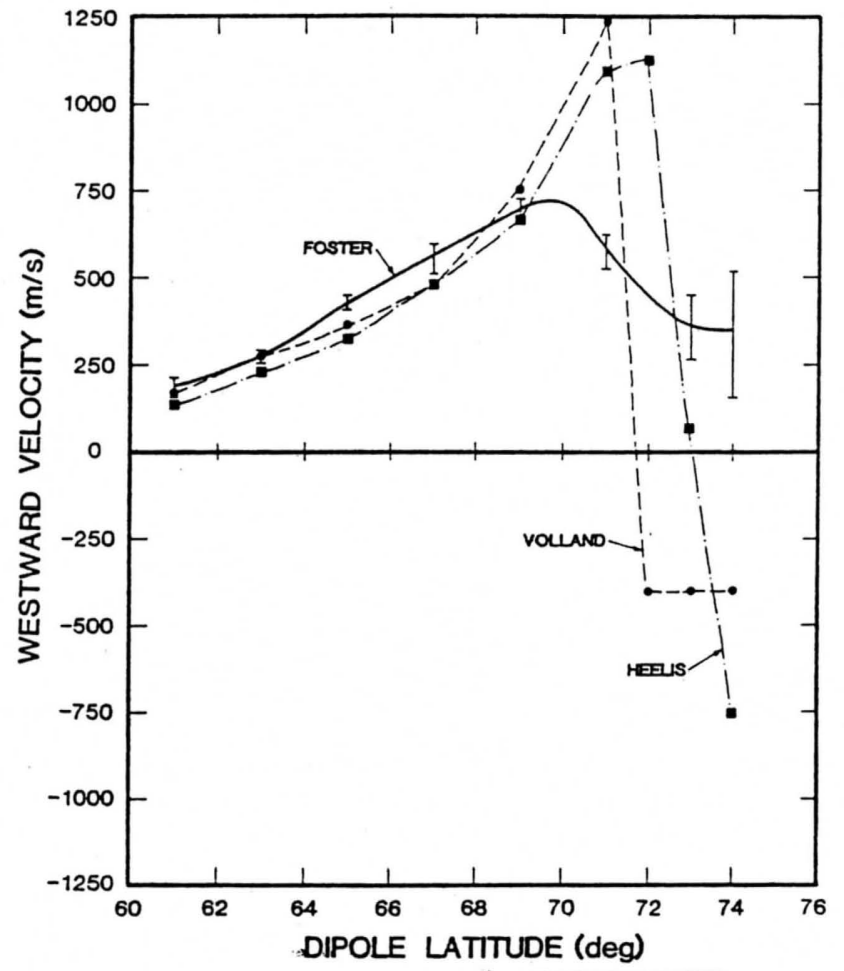

Fig. 6. Quantitative comparison of model westward convection velocities at $1800 \mathrm{MLT}$ as a function of the authors'dipole latitude. The three models (Foster, Volland, and Heelis) correspond to those used in Figures 5 to 7 .

activity levels, with June 29, 1978, having a different IMF sector. All three sets of westward drifts show very weak flows; the June 23, 1978, data come from a "quiet" period after some relatively fast flows ( $\gtrsim 1.5 \mathrm{~km} / \mathrm{s})$; June 29,1978 , represents a very quiet flow period 1 hour before very intense westward flows $(\gtrsim 1.5 \mathrm{~km} / \mathrm{s}$ ); finally, the July 14,1979 , data set was obtained from the quietest period, where the average $K p$ had dropped to $\sim 2^{-}$[see Foster et al., 1981]. Excluding these three data sets from Figure 7 would, at 1800 MLT, produce a more consistent latitudinal variation. The westward flow would peak in the $68^{\circ}$ to $72^{\circ}$ latitudinal range. However, still only three data sets would show the reversal to eastward flow at higher latitudes. Even the three data sets which do indicate eastward flows (June 22, 1978, July 18,1979 , and July 19,1979 ) do not look very similar to the Volland [1978] or Heelis [1983] profiles shown in Figure 6. Clearly, the use of a least squares fit or other fitting methods to obtain a closer agreement between the Volland or Heelis models and the Foster empirical model would produce a better average fit, but yield no additional physical insight.

When other local times near 1800 MLT are also considered, the significance of the flow reversal shown in Figure 7 becomes even more questionable [see Foster et al., 1981]. The groundbased incoherent scatter radar data in general show the westward velocity to decrease "slowly" with latitude [Evans et al., 1980; Foster et al., 1981]. In fact, this trend had been observed previously by satellite electric field observations in the dawn-todusk meridian [Heppner, 1972, 1977]. However, some satellite observations indicate relatively sharp (shear) westward-eastward flow reversals [Heelis et al., 1976, 1983]. All these satellite and ground-based data, although at times widely different, are not in conflict with each other but simply highlight our lack of understanding of ionospheric electric field phenomena. From a modeling viewpoint, the difference between using simple Vol- land or Heelis models, or more sophisticated models, or even empirical average models is physically not important. At present, the simple models appear to adequately represent ionospheric convection in an average sense, as would empirical models or sophisticated models [Feldstein et al., 1984]. With improved multistation, including cleft, polar cap, and Harang region convection observations, the observations may well lead to some differentiation between the simple Volland and Heelis models.

\section{SUBSTORM AND IMF EFFECTS}

The model-data comparisons discussed in the previous section involved average rather than instantaneous convection patterns. However, as the incoherent scatter radars probe the ionosphere, the plasma convection pattern may change with time, and this would further complicate the effort to deduce the convection pattern from the measured velocities. In order to determine the possible problems associated with observing a time-dependent convection pattern, we will assume a simple substorm variation and then show what would be observed by the EISCAT, Millstone Hill, and Chatanika radars.

For our substorm variation, we adopted the convection model described by Sojka and Schunk [1983]. This model describes a substorm of a few hours duration, with a 1-hour growth phase, a 1.5-hour main phase, and a 3-hour recovery phase. During the substorm, the convection pattern changes from a symmetric two-cell pattern with a $20-\mathrm{kV}$ cross-tail potential to an asymmetric two-cell pattern with enhanced plasma flow in the dusk sector and a total cross-tail potential of $90 \mathrm{kV}$. Also, during the main phase the polar cap radius expands from $14.8^{\circ}$ to $16.3^{\circ}$ of latitude. Further details are given by Sojka and Schunk.

Figure 8 shows the Sojka and Schunk [1983] storm convec-

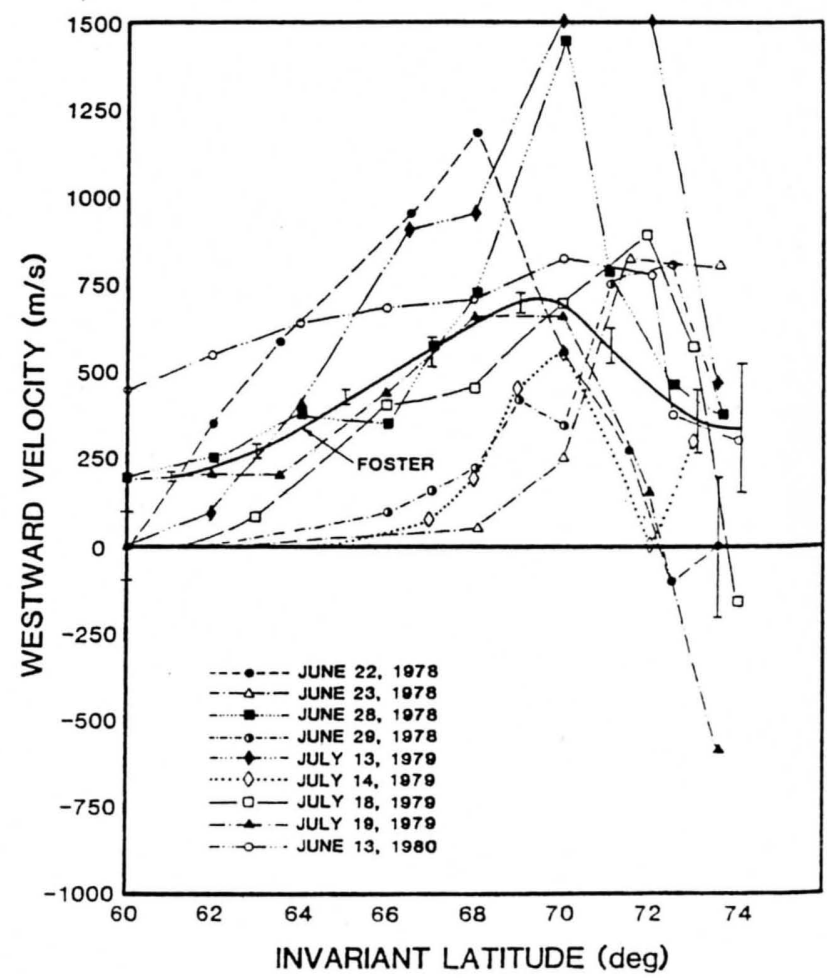

Fig. 7. Quantitative comparison of the Foster model westward convection velocities and the individual Chatanika observations at 1800 MLT as a function of invariant latitude [from Foster et al., 1981]. 


\begin{tabular}{|l|l|l|l|l|}
\hline $100 \mathrm{M} / \mathrm{S} \cdot$ & $200 \mathrm{M} / \mathrm{s}-$ & $500 \mathrm{M} / \mathrm{S} \rightarrow$ & $1000 \mathrm{M} / \mathrm{s} \rightarrow$ & $2000 \mathrm{M} / \mathrm{S} \longrightarrow$ \\
\hline
\end{tabular}
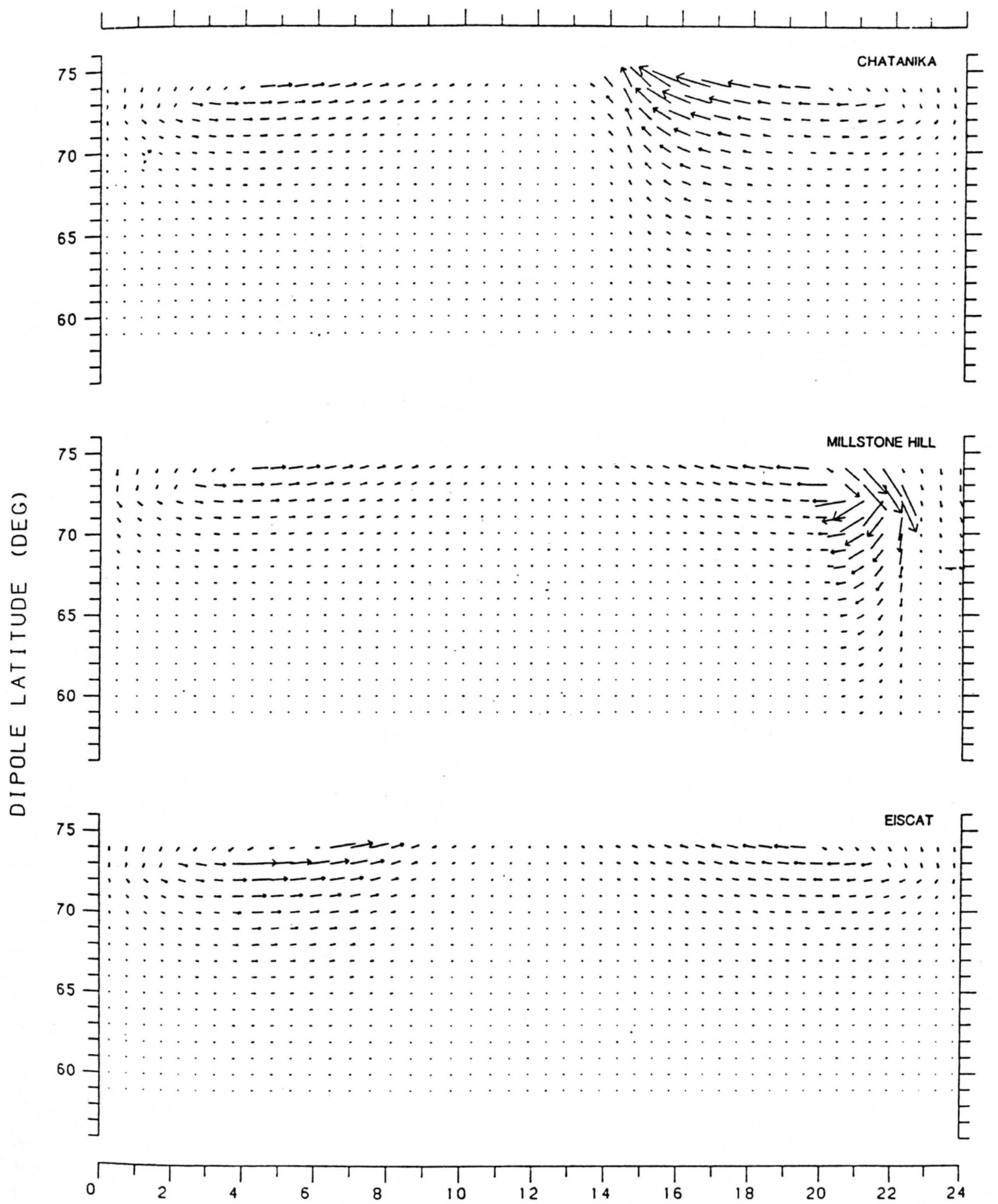

ML T (HR)

Fig. 8. Model magnetospheric storm convection velocities used by Sojka and Schunk [1983] presented in the authors'dipole latitude-MLT reference frame. Convection patterns are shown for three locations: EISCAT (bottom panel), Millstone Hill (middle panel), and Chatanika (top panel). 
tion pattern in dipole coordinates for the longitudes associated with the incoherent scatter radars located at EISCAT, Millstone Hill, and Chatanika. At EISCAT, the substorm occurs in the dawn sector, while at Chatanika it is in the dusk sector and at Millstone Hill it occurs just premidnight. If the velocities at the three sites were compared to find a unique convection pattern and the substorm aspect was overlooked, the data from the three sites could not be unified. Similarly, data sets from one longitude cannot be interpreted unambiguously if substorm effects are overlooked; i.e., the EISCAT data could be erroneously interpreted as a constant potential distribution with a larger dawn sector potential.

The storm variations simulated in Figure 8 are not too dissimilar to the variations found in radar data sets. Figures $5 a$ and $5 b$ in the work by Foster et al. [1981] compare Millstone Hill and Chatanika convection velocities; the two sets of patterns show several cases where over a period of less than $30 \mathrm{~min}$ the convection velocities increase at the same UT, but at different MLT's. Another case study involving three different longitudes is given by de la Beaujardiere et al. [1983]. In that study a total of five substorms were identified with data from Millstone Hill and Chatanika. For some of the substorms, velocity enhancements were observed at both Chatanika and Millstone Hill, while for others only one, or none, of the radars observed enhancements. The question of the local or global nature of a substorm still remains to be resolved, but as the Foster et al. and the de la Beaujardiere et al. studies show the substorm effects are significant. At this time it would appear that the model substorm portrayed in Figure 8 is not inconsistent with substorm signatures. However, the uniqueness or physical interpretation of the substorm model still awaits resolution.

In addition to the substorm, which is at present considered to be primarily a "triggered" magnetospheric phenomenon, the electric field responds to IMF variations. The solar wind is the energy source for the electric field generator, but to some extent the generator's efficiency and distribution are closely coupled to the IMF. Observationally, Heppner [1972] was able to show the importance of IMF variations on the dawn-to-dusk ionospheric electric field. More recently, Heelis [1984], using Atmospheric Explorer C convection data, and Burch et al. [1985], using Dynamics Explorer(DE) 1 and 2 data, have refined these empirical relationships with the IMF. Indeed, beginning with the work of Crooker [1979a, $b ; 1980]$, the DE data were used to augment simple IMF-dependent ionospheric convection patterns by Reiff and Burch [1985]. These patterns, although still relatively simple, are all considerably more complex than the Volland or Heelis two-cell patterns. At present, the data indicate that the trends obtained from these simple physical considerations are relevant to the magnetospheric electric field distribution. IMF dependences are also included in more sophisticated current-conductivity models [Feldstein et al., 1984]. However, at this time the significance and uniqueness of such modeling are uncertain. Feldstein et al. compare their model results with satellite and ground-based radar data as well as with the Foster [1983] empirical model. These comparisons look favorable; however, obtaining agreement with the Foster empirical model does not itself show a conclusive IMF dependence (see earlier discussion in Section 4, Figure 7).

\section{SUMMARY AND DISCUSSION}

The uncertainties associated with the transformation modelers use do not constitute a major problem at this time. Similarly, the problem of corotation not being UT dependent in the mag- netic frame is negligible in view of the fact that corotation is assumed to contribute at high latitudes, but is not proven. In addition, the MLT variation of Figure 2 is quite different for a tilted W. P. Olsen and K. A. Pfitzer (unpublished manuscript, 1977) model than for the dipole model. As a consequence, the UT (diurnal) variation of the corotation velocity will depend strongly on the magnetic reference frame adopted as well as on the assumption made about how $F$ region corotation is generated. When plasma drift velocities can be measured with a precision of $\widetilde{<} 10 \mathrm{~m} / \mathrm{s}$ at several longitudes, it may be possible to determine the degree to which the $F$ region corotates. By measuring average drift velocities at mid-latitudes with a precision better than $10 \mathrm{~m} / \mathrm{s}$ over a long time period, it should be possible to remove substorm trends and determine the underlying UT (diurnal) modulation.

At the present time, it is not possible to select a unique magnetic coordinate system; a wide range of dipole magnetic coordinates are comparable to the IGRF 80 model invariant latitude, MLT coordinates. However, none of these coordinates give accurate magnetospheric magnetic field variations. Indeed, within the range of possible dipole axis locations, significant variations in MLT and latitude occur for data sets acquired at different longitudes. This problem may, to some extent, be open to experimental observation, since data sets acquired at different longitudes can be presented in the different coordinate frames. The frame in which the convection patterns obtained at different longitudes (sites) gives closest agreement is the favored reference frame. This procedure, however, requires that UTdependent substorm or IMF variations can be determined and taken into account.

The problem associated with variations in the magnetospheric electric field is the most critical one. Figure 7 shows that the velocity variation seen in 9 convection data sets for approximately "similar" magnetic and IMF conditions is much larger than the magnitude of their average. Such variations can, in some cases, be attributed to substorms [de la Beaujardiere et al., 1983], IMF orientation [Burch et al., 1985] or a change in the overall level of magnetic activity $(K p)$. Hence the ionospheric signature of the magnetospheric electric field has at least three distinct dependencies:

$$
E(\mathrm{t})=E(\mathrm{Kp}, \mathrm{IMF}, \text { substorm, } \mathrm{t})
$$

where $E(\mathrm{t})$ is the ionospheric convection electric field associated with a corotating observer, which is a function of time and is what a modeler needs. The modeler would like these three dependencies to appear as a linear superposition of three electric fields, although this may not be the case in the real world.

The modelers' $K p$ dependence is the conventional two-cell electric field, which scales with the average magnetic activity index $K p$. This term, although the one most used, is still only known with zeroth-order precision. It is assumed that the variations in " $K p$ " produce instantaneous changes in the electric field, a crude assumption at best.

The remaining two dependencies, IMF and substorm, are assumed to represent the fluctuations to this $E(K p, \mathrm{t})$ model. The IMF dependence has been known for some time [Heppner 1972 , 1977]. Heppner was able to show how the asymmetry of the two-cell pattern varies with IMF orientation. This work has been further refined by Burch et al. [1985] and Reiff and Burch [1985], who using recent Dynamics Explorer data and the simple, but physical, merging model of Crooker [1980], have shown a fairly systematic correlation between IMF and DE electric field measurements. At present, this work is in an early quantita- 
tive stage. The IMF is known to vary on short time scales (minutes) and can be inhomogeneous on a small spatial scale (kilometers). Consequently, the magnetospheric electric field is expected to display similar temporal fluctuations and inhomogeneities. The question of a time delay between IMF variations and ionospheric variations needs to be studied, as does the question of how inhomogeneities are transported into the magnetospheric system from the solar wind. These problems can be tackled by coordinated ground and satellite observations.

The last dependence, substorm, has always been associated with the magnetosphere's ability to suddenly change state, i.e., auroral substorms. Since the sudden triggering mechanism is not well understood, the electric fields associated with substorms are also poorly known. Somehow, observational data sets must be used from multiple sites to try and determine empirically how global a substorm is. In modeling studies [i.e., Sojka and Schunk, 1983] the magnetic storms were assumed to be global. At present, no method of modeling or simulating local substorms is available, let alone any method of simulating the effects of parallel electric fields along auroral field lines.

Acknowledgments. This research was supported by NASA grant NAGW-77 and NSF grant ATM-84-17880 to Utah State University.

The Editor thanks the two referees for their assistance in evaluating this paper.

\section{REFERENCES}

Burch, J. L., P. H. Reiff, J. D. Menietti, R. A. Heelis, W. B. Hanson, S. D. Shawhan, E. G. Shelley, M. Sugiura, D. R. Weimer, and J. D. Winningham, IMF $B_{y}$-Dependent plasma flow and Birkeland currents in the dayside magnetosphere, 1, Dynamics Explorer observations, $J$. Geophys. Res., 90, 1577, 1985.

Crooker, N. U., Dayside merging and cusp geometry, J. Geophys. Res., 84, 951, 1979a.

Crooker, N. U., Antiparallel merging, the half-wave rectifier response of the magnetosphere, and convection, Eur. Space Agency Spec. Publ., ESA SP-148, 343, $1979 b$.

Crooker, N. U., The half-wave rectifier response of the magnetosphere and antiparallel merging, J. Geophys. Res., 85, 575, 1980.

de la Beaujardiere, O., J. Holt, and E. Nielsen, Early MITHRAS results: The electric field response to substorms, Radio Sci., 18, 981, 1983.

Doupnik, J. R., P. M. Banks, M. J. Baron, C. L. Rino, and J. Petriceks, Direct measurements of plasma drift velocities at high magnitude latitudes, J. Geophys. Res., 77, 4268, 1972.

Evans, J. V., J. M. Holt, W. L. Oliver, and R. H. Wand, Millstone Hill incoherent scatter observations of auroral convection over $60^{\circ} \leq \Lambda \leq$ $75^{\circ}, 2$, Initial results, J. Geophys. Res., 85, 41, 1980.

Feldstein, Y. I., A. E. Levitin, D. S. Faermark, R. G. Afonina, and B. A. Belov, Electric fields and potential patterns in the high-latitude ionosphere for different situations in interplanetary space, Planet. Space Sci., 32, 907, 1984.

Foster, J. C., An empirical electric field model derived from Chatanika radar data, J. Geophys. Res., 88, 981, 1983.

Foster, J. C., J. R. Doupnik, and G. S. Stiles, Large scale patterns of auroral ionospheric convection observed with the Chatanika radar, $J$. Geophys. Res., 86, 11357, 1981.

Greenwald, R. A., W. Weiss, E. Nielsen, and N. R. Thomson, Stare: A new radar auroral backscatter experiment in northern Scandinavia, Radio Sci., 13, 1021, 1978.

Haerendel, G. R., R. Lust, and E. Reiger, Motion of artificial ion clouds in the upper atmosphere, Planet. Space Sci., 15, 1, 1967.

Heelis, R. A., The effects of interplanetary magnetic field orientation on dayside high-latitude ionospheric convection, J. Geophys. Res., 89, 2873, 1984.

Heelis, R. A., W. B. Hanson, and J. L. Burch, Ion convection velocity reversals in the dayside cleft, J. Geophys. Res., 81, 3803, 1976.
Heelis, R. A., J. K. Lowell, and R. W. Spiro, A model of the highlatitude ionospheric convection pattern, J. Geophys. Res., 87, 6339, 1982.

Heelis, R. A., J. C. Foster, O. de la Beaujardiere, and J. Holt, Multistation measurements of high-latitude ionospheric convection, J. Geophys. Res., 88, 10111, 1983.

Heppner, J. P., Polar cap electric field distributions related to the interplanetary magnetic field direction, J. Geophys. Res., 77, 4877, 1972.

Heppner, J. P., Empirical models of high-latitude electric fields, $J$. Geophys. Res., 82, 1115, 1977.

IAGA Division 1, Working Group 1, International geomagnetic reference fields: DGRF 1965, DGRF 1970, DGRF 1975, and IGRF 1980, EOS Trans. AGU, 62, 1169, 1981.

Kelley, M. C., G. Haerendel, H. Kappler, F. S. Mozer, and U. V. Fahleson, Electric field measurements in a major magnetospheric substorm, J. Geophys. Res., 80, 3181, 1975.

Maynard, N. C., Electric field measurements across the Harang discontinuity, J. Geophys. Res., 79, 4620, 1974.

Mozer, F. S., and P. Lucht, The average auroral zone electric field, $J$. Geophys. Res., 79, 1001, 1974.

Mroz, G. J., W. P. Olson, and K. A. Pfitzer, Induced magnetospheric electric fields, in Quantitative Modeling of Magnetospheric Processes, AGU, Washington, D.C., 1979.

Muldrew, D. B., and J. F. Vickrey, High-latitude F region irregularities observed simultaneously with ISIS-1 and the Chatanika radar, $J$. Geophys. Res., 87, 8263, 1982.

Oliver, W. L., J. M. Holt, R. H. Wand, and J. V. Evans, Millstone Hill incoherent scatter observations of auroral convection over $60^{\circ} \leq \Lambda \leq$ $75^{\circ}, 3$, average pattern versus $K p, J$. Geophys. Res., 88, 5505, 1983.

Quegan, S., G. J. Bailey, R. J. Moffett, R. A. Heelis, T. J. FullerRowell, D. Rees, and R. W. Spiro, A theoretical study of the distribution of ionization in the high latitude ionosphere and the plasmasphere: First results on the mid-latitude trough and the light-ion trough, J. Atmos. Terr. Phys., 44, 619, 1982.

Rees, D., M. F. Smith, and R. Gordon, The generation of vertical thermospheric winds and gravity waves at auroral latitudes, II, Theory and numerical modeling of vertical winds, Planet. Space Sci., 32, 685, 1984.

Reiff, P. H., and J. L. Burch, IMF $B_{y}$-dependent plasma flow and Birkeland currents in the dayside magnetosphere, 2, A global model for northward and southward IMF, J. Geophys. Res., 90, 1595, 1985.

Sojka, J. J., and R. W. Schunk, A theoretical study of the high-latitude $F$ region's response to magnetospheric storm inputs, J. Geophys. Res., 88, 2111, 1983.

Sojka, J. J., W. J. Raitt, and R. W. Schunk, Effect of displaced geomagnetic and geographic poles on high-latitude plasma convection and ionospheric depletions, J. Geophys. Res., 84, 5943, 1979.

Sojka, J. J., J. C. Foster, W. J. Raitt, R. W. Schunk, and J. R. Doupnik, High-latitude convection: Comparison of a simple model with incoherent scatter observations, J. Geophys. Res., 85, 703, $1980 a$.

Sojka, J. J., R. W. Schunk, and W. J. Raitt, A plasma convection model, CASS report, Utah State Univ., Logan, Utah, $1980 b$.

Sojka, J. J., J. C. Foster, P. M. Banks, and J. R. Doupnik, Mapping electrostatic potentials from the ionosphere to the magnetosphere, Planet. Space Sci., 31, 1329, $1983 a$.

van Eyken, A. P., H. Rishbeth, D. M. Willis, and S. W. H. Cowley, J. Atmos. Terr. Phys., 46, 635, 1984.

Volland, H., A model of the magnetospheric electric convection field, $J$. Geophys. Res., 83, 2695, 1978.

R. W. Schunk and J. J. Sojka, Center for Atmospheric and Space Sciences, Utah State University, Logan, UT 84322-3400.

(Received September 6, 1983; revised July 29, 1985; accepted August 20, 1985.) 